\title{
De la inutilidad a la justificación de una "Forma del dedo" en Platón (De la República al Sofista)
}

\section{From Uselessness to Justification of a "Finger's Form" in Plato (From Republic to Sophist)}

\author{
Néstor-Luis CORDERO \\ https://orcid.org/0000-0003-3198-7744 \\ Université de Rennes 1, Francia \\ nestor.luis.cordero@gmail.com
}

Resumen: En la República (523a), Platón considera innecesaria la existencia de una Forma del dedo, pues no puede imaginase un no-dedo, mientras que en el Libro X afirma la existencia de una Forma de la cama, un objeto sustancial como el dedo. Esta imprecisión platónica respecto de las Formas de sustancias se confirma en el Parménides, cuando Sócrates confiesa dudar al respecto. Este artículo encuentra en un diálogo posterior, el Sofista, una respuesta coherente. La Forma de lo Otro justifica que, respecto de un dedo, haya su contrario, un "no-dedo", que es simplemente algo diferente del dedo.

Palabras clave: Platón, Forma, Parménides, República, Sofista

Aвstract: While in Republic (523a) Plato considers there is no need of the existence of a Finger's Form, since a no-finger can be imagined, in Book X he affirms the existence of a Bed's Form, a substantial object such as the finger. This Platonic inaccuracy related to the Form of substances is confirmed in the Parmenides, when Socrates confesses his doubts about them. But in the Sophist, a later dialogue, we find a coherent response because The Form of the Other justifies that there be an opposite to the finger, a "no-finger", which is simply something different from the finger.

Keywords: Plato, Form, Parmenides, Republic, Sophist

RECIBIDO: 25/05/2020 • ACEPTADO: 14/08/2020 • VERSIÓN FINAL: 18/09/2020

Quizá la inagotable riqueza de la filosofía de Platón se deba a que nunca escribió un tratado para explicar su concepción de la realidad, y como por 
entonces no existían las enciclopedias, los diccionarios filosóficos y menos aun los reportajes (escritos u orales), quien se interese en su pensamiento debe forzosamente imaginar que dialoga con el filósofo, que se coloca en el lugar de alguno de los interlocutores de Sócrates, si bien sabe que no obtendrá respuesta alguna. El mismo Platón escribió que "los textos son como las pinturas: no responden a quien las interroga". ${ }^{1}$ Pero el hecho de haber escrito "diálogos" y no tratados, nos permite seguir, como en un documental, el intercambio de ideas, del cual surge a veces un producto que los historiadores de la filosofía resumen en la frase "Platón dice que...".

En este breve trabajo hemos decidido privilegiar un caso atípico que se encuentra en un diálogo también atípico, en el cual no se puede encontrar la frase precedente, simplemente porque Platón dice que... "no sabe qué decir". El diálogo es el Parménides y el pasaje en cuestión es la línea 130c3, en la cual Sócrates joven (que no es otro que Platón, hasta el momento previo a la escritura del Parménides) confiesa que, en ese caso - que ya veremos, se encuentra en un camino sin salida, en "una dificultad (غ̇v ỏrogía)".

Nuestra interpretación de la frase citada supone un parti pris - o, si se quiere, un prejuicio - que preferimos exponer antes de analizarla. Cuando la Academia tiene casi veinte años de existencia, ${ }^{2}$ Platón, que acaba de regresar de una estadía bastante azarosa en Sicilia, escribe el diálogo que acabamos de calificar de "atípico", el Parménides. Por razones que ignoramos, Platón expone en dicho diálogo, de manera esquemática pero fiel a cuanto siempre dijo, su concepción de la realidad, en especial el papel que juegan las realidades en sí, que él llama "Formas". Pero el diálogo es atípico porque, contrariamente a lo que ocurre en otras ocasiones, Sócrates, portavoz de Platón, es incapaz de responder a las objeciones y a las críticas formuladas por su interlocutor. El caso es curioso porque Platón es el autor, al mismo tiempo, tanto de la presentación canónica de sus ideas, como de las críticas formuladas por un extranjero de Elea, el venerable Parménides, en una reunión que tiene lugar en Atenas. Dado este desdoblamiento, podemos decir que asistimos a un diálogo de Platón consigo mismo: el Platón previo al Parménides, representado por un Sócrates rejuvenecido (Platón I), y el Platón "actual", personificado por Parménides (Platón II).

Ahora bien, ¿por qué razón - comentarios de alumnos competentes, críticas de colegas, etc. - Platón decidió, pasados los sesenta años, ${ }^{3}$ someterse a ese ejercicio de autocrítica? Nunca lo sabremos. Sea como fuere, y sin

\footnotetext{
${ }^{1}$ Pl., Phdr., 275d. Todas las traducciones son del autor.

2 Platón tendría poco más de sesenta años. L. Brisson sostiene que, sin duda, el diálogo fue escrito con posterioridad al año de 370 (1992, p. 14). Diógenes Laercio (III.7) y otras fuentes biográficas sostienen que la fundación de la Academia se llevó a cabo cuando Platón regresó de un viaje a Oriente, fecha que se ubica alrededor de 387.

${ }^{3}$ Ver nota 2.
} 
caer en la filosofía-ficción, no caben dudas - ésta es nuestra interpretación - de que, si Platón no dudó en exhibir por escrito en el Parménides algunos puntos débiles e incluso ciertos errores que encontró en su propia filosofía, es porque ya tenía preparadas las respuestas pertinentes, que serían presentadas en un diálogo quizá todavía no escrito, pero sin duda elaborado hasta en sus mínimos detalles: el Sofista. En efecto, en este diálogo, otro extranjero de Elea, nuevo y esporádico portavoz de Platón, expondrá, ante un Sócrates esta vez silencioso, una ontología renovada que corregirá todos los problemas y responderá a todas las dudas expresadas en el Parménides.

En otros trabajos nos hemos ocupado en forma detallada de esta suerte de re-fundación de su filosofía llevada a cabo por Platón en el Sofista, excepto de un punto - fundamental, por otra parte-, del cual nos ocuparemos en este artículo. Este punto merecía un tratamiento especial, ya que la manera en que Platón lo encara es diferente del enfoque utilizado para poner en evidencia otras cuestiones oscuras o contradictorias que el personaje Parménides (Platón II) detectó en la filosofía de Sócrates joven (Platón I). En todos estos casos (por ejemplo, las aporías a las que conduce la noción de participación - la Forma ¿tiene partes? - , los intermediarios entre lo sensible y lo inteligible - esbozo del "tercer hombre" - , la asimilación de las Formas a "pensamientos", etc.), el cuestionamiento del personaje Parménides se refiere a aspectos de su filosofía para los cuales el personaje Sócrates, aunque joven, tenía ya una respuesta clara y distinta (tal como se encuentra en los diálogos precedentes; Platón no hace sino repetir lo que siempre dijo, por boca de Sócrates), y que ahora le resulta imposible de defender.

El caso pendiente que nos ocupa es diferente, porque Platón admite que, respecto de dicha cuestión (de la que hablaremos en detalle más abajo) no sabe qué decir; se encuentra "غ̉v ỏro@íą". Parménides (Platón II) entonces se permite aconsejarlo, pero Sócrates (Platón I) no responde. La respuesta de Sócrates se encontrará en el Sofista, y, una vez más, en boca de un extranjero, también proveniente de Elea. Veamos ahora el contexto y la índole del problema para el cual Sócrates (Platón I) no encontró aún la solución. Se trata de un punto que concierne a la "población" del universo de las Formas; en otras palabras, se trata de responder a la cuestión: "¿De qué hay Formas?". Como es sabido, en la ficción narrada en el Parménides, Sócrates joven se vanagloria de resolver el problema de la coexistencia de los opuestos en el ámbito sensible gracias a su propia teoría, según la cual hay Formas en sí que son objeto de participación por parte de las cosas sensibles individuales, y nada impide entonces que algo individual participe de dos Formas opuestas a la vez, como él mismo, que es a la vez uno y múltiple. ${ }^{4}$

\footnotetext{
${ }^{4}$ Pl., Prm., 129b-c.
} 
Es esta certeza y, especialmente el carácter dogmático con que Sócrates (Platón I) la presenta, que invita a Parménides (Platón II) a preguntarle si él mismo lleva cabo esa distinción, ${ }^{5}$ afirmando que hay una Forma de la semejanza, de la desemejanza, de lo uno, de lo múltiple, de lo justo, de lo bello, de lo bueno. Evidentemente, la respuesta de Sócrates es afirmativa. Pero Parménides insiste y le sugiere nuevos ejemplos: “¿Tú propones también una cierta Forma en sí del hombre, del fuego y del agua?". ${ }^{6} \mathrm{La}$ respuesta de Sócrates es el objeto de nuestro trabajo: "Respecto de esas [co-

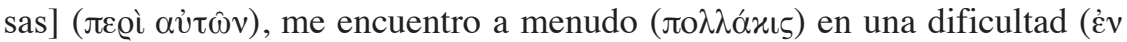

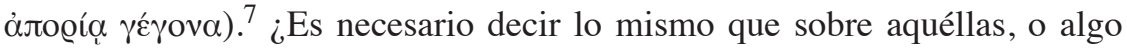
diferente?". Volveremos sobre esta respuesta dubitativa. Por el momento, retomemos el cuestionamiento de Parménides (Platón II), que, sin dudas, quiere poner a prueba la coherencia (o no) de la filosofía de Sócrates (Platón I): "Y respecto de esas cosas que a algunos les parecen ridículas, como el pelo, el barro y la basura, y otras por el estilo, sin valor e inferiores, ¿te ves [también] en la dificultad (àjoøєís) de decir que es necesario que haya o no también de cada una de ellas una Forma separada, distinta de [los objetos] que están al alcance de la mano ${ }^{8}$ ( $\mu \varepsilon \tau \alpha \chi \varepsilon\llcorner\varrho \iota \zeta o ́ \mu \varepsilon \theta \alpha)$ ?". ${ }^{9}$

Ante estos ejemplos, la respuesta de Sócrates ya no es dubitativa, pues responde con un rotundo "oủঠ $\alpha \mu \hat{\varsigma} \varsigma$ ", "en modo alguno", y agrega que estaría fuera de lugar (ótoлоv) pensar que hay una cierta Forma de esas cosas. Y la reflexión de Sócrates joven continúa: "No obstante, mucho me pregunté si no habría que decir lo mismo respecto de todas las cosas. Pero, apenas consideré esta posibilidad, me alejé rápidamente de ese punto de vista, por temor a caer en el abismo de la charlatanería $(\phi \lambda v \alpha \varrho i ́ \alpha)$. Es así como regresé a mi refugio y considero que sólo hay Formas de las cosas que ya admitimos, y a ellas consagro mis esfuerzos". ${ }^{10}$

La reacción de Parménides a esta confesión da qué pensar, y es extraño que los trabajos consagrados al Parménides no se hayan detenido a estudiar esta respuesta, pues Parménides (Platón II) critica, y con severidad, esta prudencia socrática. Si Sócrates (Platón I) desdeña (el contexto nos permitiría traducir "desdeñaba") estas cosas despreciables, dice Parménides (el Platón actual) es porque aún no quedó atrapado en las redes de la filosofía. Eso significa que

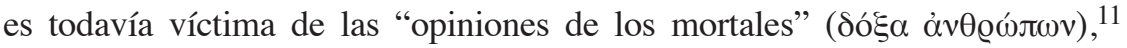
evidentísima alusión del Platón adulto al error propio del Platón joven, cuando

\footnotetext{
${ }^{5}$ Pl., Prm., 130b.

${ }^{6}$ Pl., Prm., 130c.

${ }^{7}$ Cornford 1939, p. 82.

${ }^{8}$ Es decir, de las realidades sensibles.

${ }^{9}$ Pl., Prm., 130c5-d2.

${ }^{10}$ Pl., Prm., 130d3-9.

${ }^{11}$ Pl., Prm., 130e4.
} 
aún se encontraba en el camino erróneo descrito en el Poema de Parménides, la vía de las opiniones, y admitía tanto al ser como al no-ser. ${ }^{12}$

Retomemos nuestro pasaje. Es probable que el rotundo "oủ $\delta \alpha \mu \hat{\omega} \varsigma$ " de Sócrates se deba al carácter quizá "ridículo" o "inferior", digamos, de esos tres objetos. Pero ocurre que, si es así, el reproche de Parménides respecto de la incoherencia de Sócrates se justifica. En efecto, si Sócrates hubiese sido coherente con sus propias ideas, habría visto que entre las Formas que aceptó en las réplicas anteriores estaba la de lo Bello, y que como él mismo opuso en sus ejemplos cada Forma a su contraria (desemejanza a semejanza, multiplicidad a unidad), forzosamente debería admitir una forma de lo feo, tan inferior como el barro o la basura.

Pero esto no es lo importante. La clave de la reticencia de Platón I a admitir la existencia de Formas del hombre, del fuego, del agua, y también, con el mismo status ontológico, del pelo, del barro y de la basura, se debe a que en todos esos casos se trata de sustancias, de entidades sustantivas, no de cualidades, estados o propiedades, y, como se deduce de los ejemplos, de objetos sensibles, susceptibles de estar al alcance de la mano, ya sean "dignos", como el hombre, o "despreciables", como la basura.

La duda de Platón expresada por boca de Sócrates en el Parménides se comprende en función del papel que la Forma debe jugar en la explicación de la realidad concreta. Al comienzo de este trabajo hablamos del silencio de los diálogos, en caso de que quisiéramos interrogarlos, pero en lo que concierne a las Formas incluso el status de las mismas escapa a toda interrogación; en ese caso, el silencio sería casi total, ya que muy raramente (en sólo dos o tres ocasiones) Platón describe (dudamos en escribir "define”) sus Realidades-en sí, y el rol que las mismas cumplen.

Pero la Forma en cuestión justifica no solamente la posibilidad de conocer la presencia real de ciertas cualidades en ciertos sujetos, sino también la realidad de las mismas, su existencia. La función de la Forma del Bien consiste en otorgar a las otras Formas no sólo su esencia (oủoí $\alpha$ ), ${ }^{13}$ sino también su existencia ( ò cî̀va), y las Formas las transmiten a lo que de ellas participa (por ejemplo, la Forma de lo piadoso, la piedad). La función existencial de la Forma se aplica a la propiedad tal como el sujeto la recibe, pero no a su propia existencia. La Forma de lo Bello justifica la existencia de la belleza en María, pero no la existencia de María.

Detrás de este conocido esquema general - que nos vimos obligados a presentar por razones metodológicas; el lector eventual de estas líneas sabrá

\footnotetext{
12 Recuérdese que en un pasaje de la República — diálogo del cual nos ocuparemos más adelante - Platón dijo que "lo que llamamos opinión ( $\delta$ ó $\xi \alpha)[\ldots]$ participa a la vez del ser y del no-ser”. Pl., $R$., 478d11-e2.

${ }^{13}$ Pl., R., 509b; en Sph., 257a9 se hablará de фúoıs.
} 
perdonarnos - se esconden varias incógnitas; entre ellas, la que nos indujo a escribir este trabajo. Todo filósofo pretende que las conclusiones a las que llegó no admitan excepciones $;{ }^{14}$ ellas deben ser válidas para todo, incluso para aquellos temas que parecerían quedar fuera de la teoría general. Cuando el Sócrates joven (Platón I) del Parménides se encuentra en un callejón sin salida, el venerable Parménides (Platón II) le aconseja que aproveche su juventud para entrenarse en ese tipo de ejercicio que muchos llaman "suti-

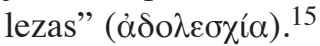

En efecto, si su teoría pretendió tener carácter universal, Sócrates no debió temer en recurrir a "sutilezas" tales como la de encontrar también una Forma como garantía para los ejemplos que Parménides le propuso... pero Sócrates dudó y, al no saber si también en ese caso hubiese sido pertinente hablar de Formas, se volvió a instalar en la comodidad de su refugio.

La duda se justificaba porque, con anterioridad al Parménides y en un mismo diálogo, Platón había negado, en un pasaje, que existiera la Forma de una realidad sustancial (ya veremos cuál) y, en otro pasaje, siempre del mismo diálogo, había ofrecido un ejemplo contrario. Es verdad que el contexto de ambos pasajes es diferente, pero el status ontológico de los dos objetos en cuestión es el mismo. Veamos el primer caso.

El contexto del pasaje de la República al que hicimos alusión se refiere al conocimiento. ${ }^{16}$ Poco después de la alegoría de la caverna, Platón hace una lista de los conocimientos que debe poseer quien va a dirigir la ciudad, $\mathrm{y}$, como resumen, dice que todos ellos deben conducir al ejercicio pleno de la vónoıs, que es la visión directa de las Formas. Pero Platón aclara que, en general, la vółoıs no es usada correctamente. ¿Por qué? Porque a veces se la despilfarra, aplicándola a cosas que no la necesitan, ya que para juzgar ( œڤเveîv; Platón evita el verbo "conocer") ciertas cosas la percepción es suficiente. Es entonces cuando entramos de lleno en nuestro tema: "Las cosas

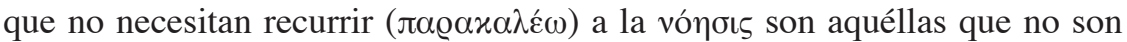
susceptibles de originar al mismo tiempo una sensación contraria". ${ }^{17}$

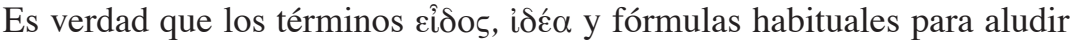
a las Formas están ausentes de este pasaje. Pero todo el contexto gira en torno a la vónбıs, y en pasajes precedentes, en especial en la imagen de la línea dividida, la vónoıs es la actividad de la parte superior del alma, del vov̂s, que contempla las Formas. O sea que, aunque el término "Forma" no aparezca, Platón da a entender elípticamente que sólo hay Formas de aquello que admite una "sensación contraria".

\footnotetext{
14 Platón expone claramente dichas conclusiones en uno de los raros pasajes en que habla "sobre" las Formas en Phd., 99d-100a.

${ }^{15}$ Pl., Prm., 135d.

${ }^{16} \mathrm{Pl} ., R ., 523 \mathrm{a}$.

${ }^{17}$ Pl., R., 523b9.
} 
Este breve pasaje resume la función que la Forma ocupa en los casos concretos que se encuentran desperdigados en los diálogos. Como siempre se trató de saber, gracias al conocimiento de la Forma, si un "x" posee determinada cualidad, ${ }^{18}$ en el caso de que no la poseyera, " $x$ " participaría de la negación de la cualidad (en nuestro ejemplo, de la desigualdad). No hay un término medio porque el "no" es sinónimo de lo contrario. En el universo de la cantidad, por ejemplo, algo es uno o no-uno, o sea, múltiple; en el de las matemáticas, un número es par o no, o sea, impar; en el ámbito del tamaño, algo es grande o no-grande, o sea, pequeño (recién en el Sofista que, como sostenemos, resolverá los problemas pendientes en Platón I, se encontrará la solución). Pero ocurre que sólo las propiedades, las cualidades, los atributos, los accidentes, los estados, son susceptibles de admitir un contrario. No es el caso de las sustancias.

El ejemplo que Platón propone es el de un dedo, y su respuesta es clara y

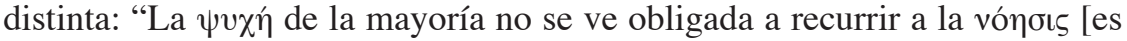

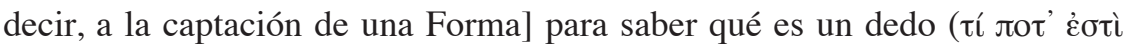

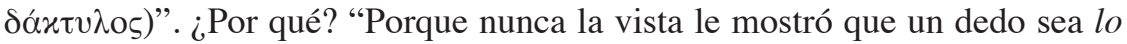

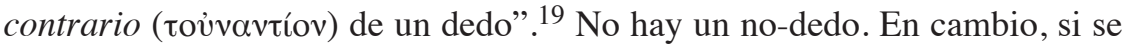
trata de saber si un dedo es grande o pequeño, en ese caso sí que hace falta $\dot{\varepsilon} \pi\left\llcorner\right.$ Һолєіิv, ${ }^{20}$ es decir, hay que investigar, porque, antes de pronunciarse, el alma debe preguntarse qué es lo grande, qué es lo pequeño. Platón no dice nada más, pero otros contextos nos muestran que se tratará de saber si lo grande, o lo pequeño, que son Formas, están presentes en el dedo.

Parecería entonces que, respecto del conocimiento de una sustancia, no se aplica el mismo procedimiento que se utiliza para conocer sus propiedades o su estado. Las Formas justificarían la existencia real de las propiedades de la sustancia (en la presente ocasión, la grandeza o pequeñez del dedo), lo cual permite conocerlas objetivamente, científicamente. Pero no justifican la existencia de la sustancia, es decir, del dedo. Si se quiere saber qué es un dedo, basta con mirarlo. No hay una Forma del dedo, porque no hace falta.

Pero ocurre que en el mismo diálogo Platón dirá, más adelante, de manera clara y distinta, que hay Formas por lo menos de dos entidades sustanciales, como había sido el caso del dedo, y se explayará respecto de una de ellas. En este caso no hay referencias al conocimiento; es el aspecto ontológico de la Forma el que está en juego, pero no para conocerla, sino en tanto modelo de imágenes y de imitaciones que, si no existiera la Forma, no se existirían. Si hay imitación, es porque hay un modelo a imitar, y a ese modelo Platón lo llama concretamente Forma, Idea: "Hay muchas camas y muchas mesas

\footnotetext{
18 Por ejemplo, la igualdad en el caso de dos trozos de madera, en Pl., Phd., 74d.

${ }^{19} \mathrm{Pl} ., R_{\text {., }}$ 523d6.

${ }^{20}$ Pl., R., $524 \mathrm{~b} 4$.
} 
[...] pero, respecto de ellas, no hay dos Ideas (iðćaı), sino una [Idea] de la cama y una [Idea] de la mesa". ${ }^{21}$ En los párrafos siguientes Platón privilegia el ejemplo de la cama, y la terminología que utiliza es la habitual cuando se trata de las Formas: el carpintero fabrica una cama material contemplando

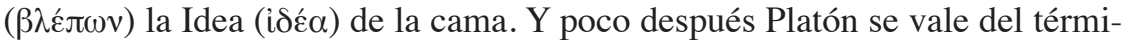

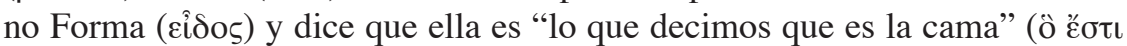

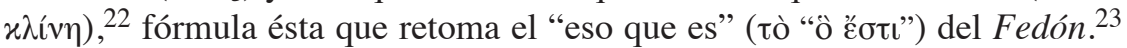
Las imitaciones copian "la cama por naturaleza ( dios, que es "lo que es la cama". ${ }^{24}$ De una realidad sustancial, el dedo, no hay Forma; de otra realidad sustancial, la cama, la hay, incluso si, evidentemente, no hay una no-cama. La duda de Platón I en el Parménides respecto de la existencia eventual de Formas "sustanciales" se justifica.

Pero el caso de la República no es único. En el Menón, a propósito de las perfecciones, se las compara con las abejas que, si bien son todas distintas, tienen algo en común, la Forma (عî̀os), ${ }^{25}$ lo cual no sería pertinente si se aplica la receta de la República, pues no hay una no-abeja. Y otro tanto ocurre en el Crátilo respecto de la lanzadera que el artesano fabrica contem-

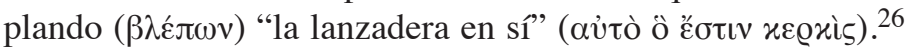

En todos los casos se trata de "sustancias". El hecho de que la cama y la lanzadera sean artefacta no introduce ningún cambio de perspectiva: son objetos sustanciales fabricados. Ni la abeja ni la cama ni la lanzadera son propiedades o cualidades o estados que admitirían la posibilidad de que hubiese las no-sustancias respectivas, lo cual obligaría a poner en juego la vónoıs para saber si "eso", por ejemplo, es una abeja o una no-abeja. O hay una abeja, o no hay nada. También en ese caso basta con mirarla... de lejos, es mejor. Entonces, ¿por qué Platón niega la existencia de una Forma como garantía del dedo, cuando la admite respecto de la abeja, la cama, y la lanzadera? Repito lo dicho: el hecho de que unos ejemplos se refieran a artefactos (cama, lanzadera) y otros a seres "naturales" (dedo, abeja), no cambia nada, porque Platón dice claramente en el Libro X que la cama en sí la creó el dios; recién la segunda cama será un artefacto. No hay Forma del dedo, por un lado; hay Forma de la abeja y de la lanzadera, por el otro. Sin caer en un parricidio, no caben dudas de que se puede afirmar que Platón es inconsecuente.

Pero si bien el diagnóstico es severo, ocurre que, como vimos, es el mismo Platón quien lo comparte en la frase dubitativa del Parménides. Ya

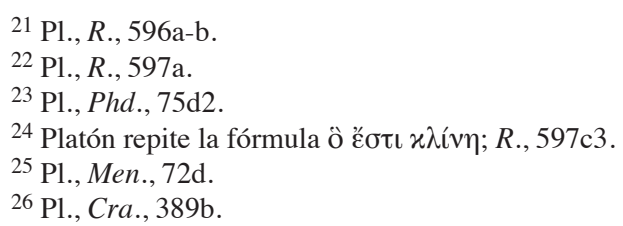


veremos que la solución llegará con el Sofista, pero, antes de escribir este diálogo, o sea, en las etapas previas también al Parménides, ¿intentó Platón superar la anomalía que consistía, dentro de su teoría, en negar el derecho a poseer una Forma como garantía a las realidades sustanciales? Sin correr el riesgo de caer en la filosofía-ficción, creemos que sí. Las sustancias no son susceptibles de ser predicados, pero para que la teoría pueda universalizarse $\mathrm{y}$, especialmente, para que las nociones de participación y de presencia tengan siempre vigencia, las Formas deben ser forzosamente predicados. Ergo, ¿habría la posibilidad de transformar las sustancias en cualidades, o sea, en predicados?

La lengua provee ya casos de sustantivos con valor cualitativo que conservan en su raíz el sustantivo de origen: humanidad (hombre), animalidad (animal), triangularidad (triángulo), esfericidad (esfera), potencialidad (potencia), fogosidad (fuego), etc. Una lengua dúctil como la griega permite crear términos semejantes. Un pasaje del Teeteto es sumamente ilustrativo. ${ }^{27}$ Platón habla de la manera en que una cosa individual adquiere una cualidad, por ejemplo, el calor, o la blancura. En realidad, como se trata de propiedades, habría que traducir literalmente que lo individual adquiere la

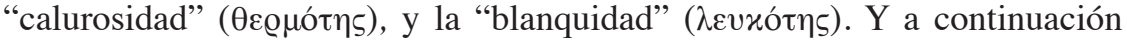
agrega que eso no significa que lo calificado, sea lo que fuere, devenga la "cua-

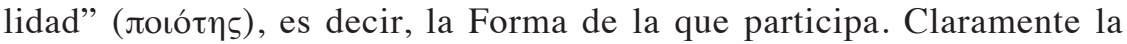
Forma está presentada como una cualidad en sí. En el contexto del diálogo,

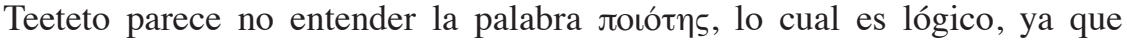
Sócrates acaba de inventarla. Todos los diccionarios etimológicos están de acuerdo, fundamentalmente Chantraine..$^{28}$ Por esta razón Sócrates le dice:

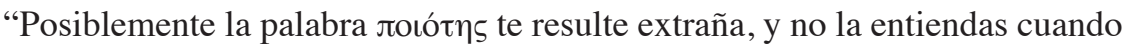

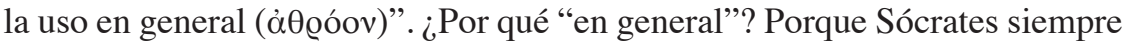
habló de "cualidades" ya individualizadas (la blanquidad, la calurosidad), y nunca de la cualidad en sí.

En esta etapa de su producción, ¿pensó Platón, además de crear la

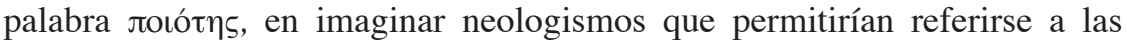
sustancias con el significado de propiedades o atributos? Evidentemente, no quedan testimonios en los diálogos, pero sí en la tradición oral. Es sabido que el enemigo íntimo de Platón, Antístenes, habría escrito en un pasaje de su diálogo Sathon, transmitido por numerosas fuentes ${ }^{29}$ que él ve un

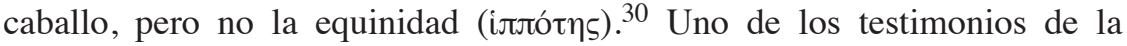
frase acompaña esta observación con una conclusión que obviamente no

\footnotetext{
27 Pl., Tht., 182a.

${ }^{28}$ Chantraine 1974, III, p. 921.

${ }^{29}$ Entre otras, Simp., in Cat., 8 b25.

${ }^{30}$ Sobre Antístenes, ver Giannantoni, G. (vol. 2, passim) y Mársico, C. (vol. 2, passim).
} 
puede pertenecer a Antístenes, en la cual Platón habría respondido: "No ves la equinidad porque no tienes los ojos para verla". Es decir que, a pesar de la crítica a Antístenes, Platón habría admitido que la palabra "equinidad" era pertinente. Si aplicamos este neologismo al uso canónico de la teoría, un caballo sería un caballo porque participaría de la equinidad, y para saber qué es un caballo hay que conocer qué es la equinidad. Nada que objetar.

Pero hay otros testimonios. En un pasaje de Amonio, ${ }^{31}$ se hace decir a

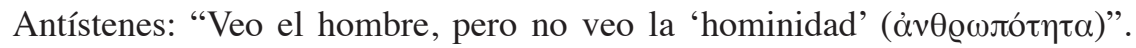
Y Diógenes Laercio da cuenta de un diálogo, muy probablemente falso, entre Diógenes el cínico y Platón, pero pertinente para nuestra hipótesis: "Cuando Platón discutía sobre las Formas y mencionaba la mesidad (

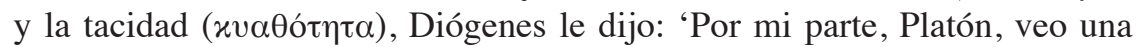
mesa y una tasa, pero no veo para nada la mesidad ni la tacidad". ${ }^{32}$ Y la respuesta de Platón coincide con la que habría dado a Antístenes en el otro testimonio: "Es lógico, dijo, porque posees los ojos que ven una mesa y una tasa, pero no tienes el intelecto (vov̂v) con el que se ve la mesidad y la tacidad". La referencia al vov̂s, por parte de Platón, confirma que, para él, se trata de Formas "visibles" sólo para el pensamiento.

En realidad, este tipo de terminología habría solucionado varios problemas. Por ejemplo, si Platón hubiese hablado de hominidad y no de hombre, el argumento del tercer hombre hubiese desaparecido. Veamos por qué. En la versión del argumento del tercer hombre tal como la presenta Alejandro de Afrodisias, ${ }^{33}$ éste dice que cuando se afirma que "el hombre

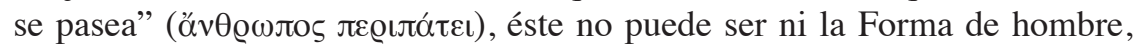
ni un individuo, pues no sabemos quién es; hay que imaginar entonces una entidad intermediaria. El argumento se refutaría si por "hombre" se entendiera "hominidad", y como en la caracterización de ésta figuraría la posibilidad de caminar, todo lo que participaría de ella podría "pasearse", ya sea Sócrates, o "el hombre", o "un hombre".

Dentro de este panorama, una referencia a la dedidad no hubiese parecido extemporánea, y, en el Parménides, a la pilosidad, a la barridad, a la basuridad. Felizmente la solución encontrada en el Sofista evitó que Platón cayera, por escrito, en estos excesos de lenguaje. Así y todo, si esta posibilidad existió, a ella pudo referirse Platón I cuando confiesa a Platón II que en cierto momento temió caer en el abismo de la charlatanería. ${ }^{34}$

${ }^{31}$ Ammon., in Porph., p. 40.

${ }^{32}$ D. L., VI, 53.

${ }^{33}$ Alex. Aphr., In Metaph., 83, 34.

${ }^{34}$ Pl., Prm., 130d8. Curiosamente, J. L. Borges, si bien no manifestó mucha simpatía por Platón, recurrió a neologismos por el estilo. En Historia de la eternidad $(1974,358)$, dice desconfiar de la existencia de una humanidad eterna, y escribe: "Formas universales mucho más arduas nos propone Platón. Por ejemplo, la Mesidad, o Mesa Inteligible, que está en los cielos, 
Antes de tratar la solución que Platón propondrá en el Sofista, podemos agregar que, curiosamente, los dos testigos más próximos en el tiempo de la filosofía de Platón, Antístenes, que era su contemporáneo (aunque unos años mayor) ${ }^{35}$ y Aristóteles, cuando se refieren a la teoría de las Formas (ambos, para criticarla), presentan el caso de ejemplos que hemos llamados sustanciales. Aristóteles, como es sabido, dice que las Formas de Platón son sustancias (oủoíal) en sí. La significación de oủoía es, evidentemente, diferente en Platón y Aristóteles, pero los pocos ejemplos que éste da, aparte de lo grande y lo pequeño, son la mesa, ${ }^{36} \mathrm{el}$ animal, el bípedo, y "el hombre

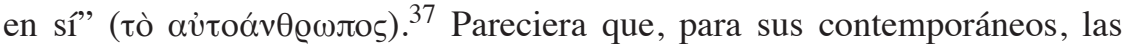
Formas que hemos llamado "sustanciales" eran las que mejor caracterizaban la filosofía de Platón. El caso de Antístenes es más interesante porque también él utiliza la fórmula "en sî" para aludir a las Formas, pero, para él, se trata de "cualidades en sî". ${ }^{38} \mathrm{Y}$ cuando ofrece ejemplos, como vimos, recurre al caballo (en el pasaje de su diálogo Sathon, ya mencionado) y al hombre (en una referencia de Amonio), o sea, dos entidades sustanciales como la cama, la abeja, la lanzadera... y el dedo.

Dejemos de lado estas elucubraciones - pues no se pueden demostrary volvamos a los diálogos, y no caben dudas de que en los escritos que precedieron al Parménides, Platón presenta en algunos casos ejemplos de Formas que no responden a su propia decisión de admitirlas. Como vimos, sólo hay Formas en los casos en los que puede existir una no-Forma correspondiente, que es su contraria: bello/no-bello, grande/no-grande, piadoso/no-piadoso, uno/no-uno. Y en los pocos ejemplos concretos que ofrece Aristóteles (para criticarlos), según narran anécdotas o testigos que leyeron las obras de Antístenes, esos ejemplos serían los más importantes. No obstante, como no podemos juzgar a Platón por lo que dicen sus detractores, debemos limitarnos a tomar como punto de partida la duda expresada por Platón I en el Parménides, que es una de las incógnitas que quedan sin resolver en ese diálogo, pero que encontrarán su respuesta en el Sofista.

Si el Parménides es un diálogo extraño, otro tanto puede decirse del Sofista, que, si lo es, es porque hereda el carácter insólito de aquél. En efecto: en el Sofista, Platón va a solucionar los problemas a los cuales

arquetipo cuadrúpedo que siguen todos los ebanistas del mundo". Y después dice que no se hubiese llegado a la mesidad sin la triangularidad. Finalmente, hace una alusión a la leonidad, que es inimaginable sin la melenidad y sin la zarpidad.

${ }^{35}$ Habría nacido entre 445 y 444. Para el nacimiento de Platón se acepta en general los años 428-427.

${ }^{36}$ Arist., Metaph., 988a.

${ }^{37}$ Arist., Metaph., 991a.

38 Ver Cordero 2001, p. 333. 
"Sócrates" no pudo responder en el Parménides, y, para un lector u oyente del nuevo diálogo, habría resultado poco convincente que, con el peso de los años, "Sócrates", hubiese sido ya "atrapado" por la filosofía, ${ }^{39}$ lo cual le permitiría proporcionar las respuestas adecuadas. Platón, que siempre encuentra una mise en scène apropiada para sus diálogos, recurre a una novedad: cambia su portavoz. Parménides en persona, en la ficción del Parménides, se había trasladado a Atenas desde su Elea natal y, a propósito de una conferencia de Zenón a la cual asiste Sócrates joven, lo puso en aprietos formulándole críticas a las que no pudo responder. En el Sofista, otro extranjero, también de Elea, ante un Sócrates prácticamente silencioso, esta vez en Atenas, corregirá los defectos que Platón había detectado en su teoría y otorgará un status dinámico a las Formas que les otorgará nueva vida.

En lo que concierne a nuestro tema, es evidente que no vamos a encontrar, literalmente, la justificación de la Forma del dedo. Encontraremos, en cambio, una nueva concepción de la relación entre ser y no-ser que puede justificar, ahora sí, la existencia de una Forma del no-dedo, condición necesaria para que exista una Forma del dedo. Se tratará, en realidad, de una consecuencia secundaria de la refutación (o de la relativización) de la concepción parmenídea de la oposición contradictoria entre ser y no-ser.

Todo comienza cuando el sofista es definido como un fabricante de imágenes, de ilusiones, ergo, de falsedades ${ }^{40}$ lo cual supone que hay realidades que parecen ser, pero que no son. Pero ya Parménides había sostenido que nada hay fuera de la alternativa ser/no-ser. Si esas realidades no son, nada puede decirse de ellas, porque "no hay no ser", ${ }^{41}$ y el sofista, contrariamente al diagnóstico de Platón, no podría fabricar ilusiones y falsedades. Para justificar su definición del sofista Platón decide entonces cuestionar la alternativa parmenídea "o ser, o no-ser", y después de un largo camino, que parte, extrañamente, de un pragmatismo inhallable en otros diálogos, ${ }^{42}$ junto a la Forma de la identidad, que había monopolizado hasta

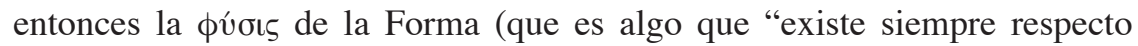

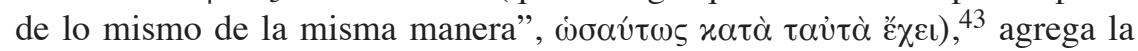
Forma de lo diferente (

Pero, jerárquicamente, como más importante que las Formas de Identidad y de Diferencia, Platón postula la existencia de la Forma del Ser (iðća

\footnotetext{
${ }^{39}$ Parménides: "Lo que ocurre, Sócrates, es que tú eres todavía demasiado joven y la filosofía no te ha atrapado aún, como - estoy seguro - te atrapará más adelante"; Pl., Prm., 130e.

${ }^{40} \mathrm{Pl} .$, Sph., 236d.

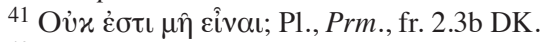

${ }^{42}$ De hecho, hay imágenes, y entonces "lo que llamamos realmente imagen ¿no existe entonces realmente? [...] Es muy probable que, de una manera muy insólita, una relación entrelace el ser y el no ser" (Sph., 240b-c).

${ }^{43} \mathrm{Pl}$., Phd., 78d.
} 


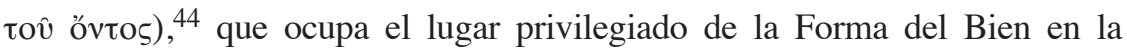
República, pero que sólo confiere existencia a las demás; de su "esencia" se ocupan las otras dos Formas privilegiadas, de las cuales participan todas las otras. Cada Forma es idéntica a sí misma y diferente de todas las otras. Pero, al ser "diferente" de las otras Formas, cada Forma "no es" la otra, sin que de ello se deduzca que no sea en absoluto. La conclusión que Platón extrae

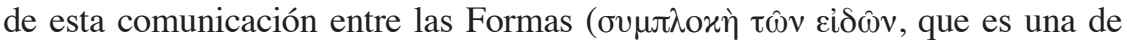
las novedades que introduce o que sistematiza - pues ya había esbozos en diálogos anteriores - el Sofista) es la siguiente: "La naturaleza de lo diferente

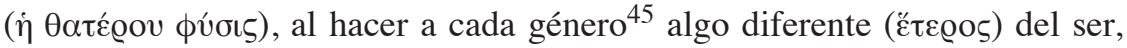
hace de él un no-ser (oủx òv)" ${ }^{46}$

En la cita precedente Platón se vale de la fórmula "oủx òv", sinónimo

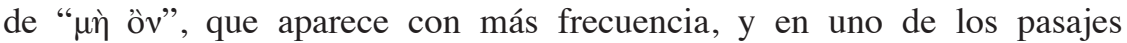
fundamentales del diálogo detalla el nuevo significado que, a partir del Sofista, adquieren dichas expresiones: "No estemos de acuerdo, entonces, cuando se diga que la negación significa lo contrario, y admitamos sólo

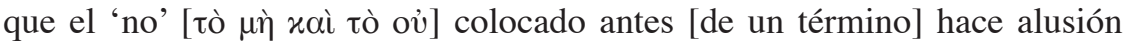
a alguna de las otras cosas respecto de los nombres que siguen, o, más aún de los hechos respecto de los cuales se colocan los nombres pronunciados después de la negación". ${ }^{47}$ En resumen, "cuando hablamos de lo que no es, no hablamos de algo contrario (Ėvavtíov) a lo que es, sino sólo de algo diferente".

En el pasaje de la República que originó este trabajo, el pensamiento (vó$\eta \sigma ı \varsigma)$ se ponía en juego "cuando las cosas percibidas suscitan una sensación contraria, ya que la percepción manifiesta tanto algo, como su contrario (غ่vavtíov)" ${ }^{48}$ Pueden prescindir del pensamiento, en cambio las que no

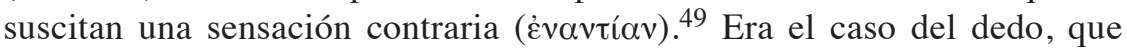

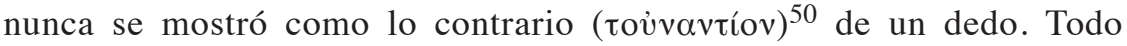
el pasaje se basa en la noción de contrariedad (el término évavtíov figura cuatro veces en menos de diez líneas), y no hace falta poner en juego el pensamiento para distinguir un dedo de un no-dedo, porque no hay un nodedo. Pero, según la innovación introducida en el Sofista, un no-dedo no es lo contrario (Èvavtíov) de un dedo, sino sólo algo diferente de un dedo, que puede suscitar una sensación diferente de la del dedo, por ejemplo, la de una

\footnotetext{
44 Pl., Sph., 254a.

${ }^{45}$ En todo este pasaje del Sofista Platón utiliza indistintamente los términos "género" (génos) y "Forma" (eîdos).

${ }^{46} \mathrm{Pl}$., Sph., 256d-e.

${ }^{47}$ Pl., Sph., 257b-c.

48 Pl., R., $523 \mathrm{c} 2$.

${ }^{49}$ Pl., R., $523 \mathrm{~b} 6$.

${ }^{50} \mathrm{Pl} .$, R., $523 \mathrm{~d} 6$.
} 
mano, a la cual también basta con mirarla, y saber así que es diferente de un dedo. Y para saber que una mano es diferente de un dedo, ${ }^{51}$ hay que saber qué es un dedo y qué es una mano, porque ahora se trata de dos realidades sustanciales justificadas cada una por una Forma.

La solución que el Extranjero de Elea (¿nos atrevemos a llamarlo Platón III?) propone en el Sofista para superar la disyuntiva de Parménides ("o ser, o lo contrario del ser, o sea, el no-ser") permite, retroactivamente, justificar la posibilidad de la existencia de una Forma del dedo.

\section{BIBLIOGRAFÍA}

\section{Fuentes antiguas}

AleXANDri Aphrodisiensis, In Aristotelis Metaphysica commentaria, ed. M. Hayduck, Berlín, G. Reimer, 1891.

Ammonius, In Porphyrii isagogen sive V voces, ed. A. Busse, Berlin, G. Reimer, 1891.

Aristotelis Metaphysica, ed. W. Jaeger, Oxford, Oxford Clarendon Press, 1957.

Laertius, Diogenes, Lives of Eminent Philosophers, ed. T. Dorandi, Cambridge, Cambridge University Press, 2013.

Los filósofos socráticos. Testimonios y fragmentos II. Antístenes, Fedón, Esquines y

Simón, ed. C. Mársico, Buenos Aires, Losada, 2014.

Platon, Parménide, trad. L. Brisson, París, GF-Flammarion, 1992.

Platon, Teeteto, trad. M. Nancy, París, GF-Flammarion, 1994.

Platonis Opera, ed. J. Burnet, Oxford, Oxford University Press, 1900-1907.

Simplici in Aristotelis Categorias Commentarium, ed. C. Kalbfleisch, Berlín, G. Reimer, 1907.

Socratis et Socraticorum Reliquiae, ed. G. Giannantoni, vol. 2, Nápoles, Bibliopolis, 1990.

\section{Fuentes modernas}

Borges, J. L., "Historia de la eternidad", Obras Completas, Buenos Aires, Emecé, 1974.

Chantraine, P., Dictionnaire Étymologique de la langue grecque, vol. III, París, Klincksieck, 1974.

${ }^{51}$ La identidad y la diferencia se aplican en "regiones", y por eso ambas justifican la definición de algo. En la "región" del tamaño, por ejemplo, está lo grande y lo no-grande, y en la parte de la diferencia contrapuesta a lo grande, está todo lo "diferente" de lo grande, entre otras cosas, lo igual (Sph., 257b). La "diferencia" no es total; decir que el caballo es diferente de la manzana no significa nada; decir que es diferente de un asno, que está en la región que abarca lo no-caballo, sí. 
Cordero, N. L., "L'interprétation antisthénienne de la notion platonicienne de 'Forme' (ềdos, idéa)", en M. Fattal (ed.), La philosophie de Platon, I, París, L'Harmattan, 2001.

Cornford, F. M., Plato and Parmenides, Londres, Routledge \& Kegan Paul Ltd., 1939.

Néstor-Luis CoRdero es egresado de la uba (doctor en Filosofía y Letras, 1973). Radicado en Francia desde 1979. Después de haber obtenido dos doctorados en la Universidad de Paris IV (Sorbona), es Profesor Emérito de la Universidad de Rennes 1. Durante varios años fue responsable de un seminario en la Sorbona, como profesor invitado especializado en filosofía griega, es autor de más de sesenta artículos en su especialidad y de la traducción al español (Madrid, 1988) y al francés (Paris, Flammarion, 1993; $7^{\text {a }}$ ed. 2003) del Sofista de Platón. Es autor de tres libros sobre Parménides, Les deux chemins de Parménide (Paris, Vrin, 1984; $2^{\mathrm{a}}$ ed. 1997), By being, it is. The thesis of Parmenides (Parmenides Publishing, Las Vegas, 2004) (trad. esp.: Siendo, se es, Buenos Aires, Biblos, 2006) y Parmenide scienziato? (Sank Augustin, Academia Verlag, 2008). Colabora regularmente con el Istituto Italiano per gli Studi Filosofici de Nápoles y en enero de 2009 fue declarado Primer Ciudadano Honorario de Elea/Velia. 